\title{
SELLING SEX: WHAT DETERMINES RATES AND POPULARITY? AN ANALYSIS OF 11.5 THOUSAND ONLINE PROFILES
}

\author{
Alicia Mergenthaler ${ }^{1}$ and Taha Yasseri ${ }^{1,2 *}$ \\ ${ }^{1}$ Oxford Internet Institute, University of Oxford, Oxford, UK \\ ${ }^{2}$ Alan Turing Institute, London, UK \\ * Corresponding Author: taha.yasseri@oii.ox.ac.uk
}

October 23, 2019

\begin{abstract}
Sex work, or the exchange of sexual services for money or goods, is ubiquitous across eras and cultures. However, the practice of selling sex is often hidden due to stigma and the varying legal status of sex work. Online platforms that sex workers use to advertise services have become an increasingly important tool in studying a market that is largely hidden. Although prior literature has primarily shed light on sex work from a public health or policy perspective (focusing largely on female sex workers), there are few studies that empirically research patterns of service provision in online sex work. Little research has been done on understanding pricing and popularity in the market for commercial sex work. This study investigates the determinants of pricing and popularity in the market for commercial sexual services online by using data from the largest UK network of online sexual services, a platform that is the "industry-standard" for sex workers. While the size of these influences vary across genders, nationality, age, and services provided are shown to be primary drivers of rates and popularity in sex work.
\end{abstract}

Keywords Sex work $\cdot$ Labor and demographic economics $\cdot$ Popularity dynamics $\cdot$ Gender $\cdot$ Online market

\section{Introduction}

Sex work, famously referred to by Rudyard Kipling in 1888 as the "most ancient profession", is ubiquitous and poorly understood (Mattson, 2015). Sex work is defined as the sale of sexual services for money or goods, and exists in many forms (Adriaenssens, Geymonat, Oso, \& Leuven, 2016). Data on sex work is notoriously unreliable and difficult to collect due to varying legality, stigma, and the tendency for individuals to move in and out of sex work (Balfour \& Allen, 2014). The market for sex work is significant worldwide; the Office for National Statistics estimated the market for sex work in the UK at 5.3 billion GBP in 2009 (ONS, 2014). Despite the largely hidden nature of sexual services, it is estimated that 85-90 percent of all sex workers are women, with an estimated 32,000 workers in London 
and approximately 72,800 prostitutes in the UK as a whole (Balfour \& Allen, 2014, UK Home Affairs Committee, 2017). Even in countries that allow the legal sale of sexual services between consenting adults, many sex workers remain secretive, as the profession is "decriminalised but not legitimate" (UK Home Affairs Committee, 2017). While terminology around selling sexual services is widely debated, the term 'sex worker' is used in this article to refer to individuals of all gender identities who exchange sexual services for money or goods.

The majority of of prior literature written on the topic of sex work has been small-scale, qualitative, or focused on specifically epidemiological applications (Rocha, Liljeros, \& Holme, 2010). Recently, more research has been conducted on the experiences and market aspects of sex work due to the accessibility of online sex work platforms. This emerging body of literature, however, has largely neglected important intersections between marketplace success, male gender, nationality, age and the services that sex workers offer (Jones, 2015). This study seeks to fill these gaps by examining the important interactions between sex worker attributes, price-setting, and popularity.

Prior literature reflects many heterogeneous processes that can lead to individuals being involved in sex work. While not exhaustive, prior research has focused on causes such as financial benefit (especially for individuals who are unable to participate in mainstream employment), homelessness and drug addiction, family breakdown, and trafficking (Balfour \& Allen, 2014). While some studies report that a majority of sex workers they interviewed were content with their working conditions and control over their work (Mai, 2009), other literature reports workers (especially street workers and victims of trafficking), being unhappy with their conditions and wanting to change their situation (Scambler, 2007).

Bettio, Della Giusta, and Di Tommaso (2017) posit that the agency and stigma of sex workers exists in a continuum across the market. Agency is defined as the ability to "influence the terms of exchange" (Bettio et al., 2017), such as having control over working hours, working conditions, and choice of clients. Workers who work at the higher end of the market experience (escorts) may experience greater agency and less stigma than their lower-end counterparts (street workers) because their work is perceived to involve greater "brain" work and less "brawn" work (Bettio et al. 2017). Furthermore, the reasons for entering sex work, completeness of information and degree of risk associated with the sex trade varies dramatically between workers who work on the street and those who work indoors (Balfour \& Allen, 2014). As Platt et al. (2011) finds in a cross-sectional study of sex workers in London, migrant workers in the UK from Eastern Europe and the former Soviet Union face increased risks of violence and sexually transmitted infections (STIs) in comparison to their UK counterparts. There are additional differences between female, male and transgender workers (Balfour \& Allen, 2014). It is widely reported that analysis of male and trans-identifying sex workers is lacking in studies of sex work (Jones, 2015). Prior studies have posited that the male sex market is largely linked to the commercial gay sex scene and that there are very few women who buy sexual services (Balfour \& Allen. 2014).

The emergence of the Internet has influenced the market for sexual services by facilitating for the exchange of detailed information between buyers and sellers and allowing for reviews and other signals of seller reputation (Cunningham \& Kendall, 2016). By analyzing Internet platforms for selling sex, there is potential for understanding the experiences of sex workers and the larger escort industry. Disentangling the drivers of rates and popularity of sex workers can help illuminate the value placed on sexual services, and the experiences of sex sellers as a whole. Studies examining the differences between buying sexual services on and offline reveal that the conversion to online platforms 
may create efficiency in the market for sex work. Efficiency is created by providing information to consumers and sellers that may have been originally hidden (Cabral \& Hortaçsu. 2010). Previously unseen traits of sellers could include signals of quality or reputation, such as a seller's rating, or a listing of services offered. Prior research suggests that the rise of online platforms, while contributing to the overall growth of the sex industry, may also contribute to the safety of sellers and buyers by reducing information asymmetries (Cunningham \& Kendall, 2016). For example, buyers may select against sellers that have a high potential of being STI-positive are selected against because there is information online about them offering higher-risk services (Cunningham \& Kendall, 2016; Kremer \& Morcom, 1998).

The analysis of sexual marketplaces is especially illustrative of some aspects of sexual preferences, as these selections happen in private. This contrasts with the analysis of dating preferences, in which there are significant status effects to public mate selection (Cunningham \& Kendall 2016). Platforms that mediate the exchange of sexual services may allow for consumers to find escorts and services that better match their preferences (Holt, Blevins, \& Fitzgerald, 2016). These lowered search costs have been especially effective in matching consumers with high-end escort services and "girlfriend experiences" (Cameron, 2016). In Holt et al. (2016), the authors also posit that information on the Internet allows buyers to select for racial preferences and specific kinds of sexual services. Furthermore, the role of platform affordances in online platforms, including search bars, and compulsory fields, can shape interactions in the marketplace for sex work, because preferred traits can easily be found and filtered on (Burgess, Marwick, Poell, Bucher, \& Helmond, 2017, Robinson, 2015).

While some research has been done to understand the pricing of sexual service and possible influences of popularity in the market, major limitations exist in the form of having granular data and large sample size. Qualitative studies suggest that the type of service and the setting of service influence rate-setting. In Cameron (2016), the authors compare on and offline rates for sex work (including escorts, massage parlors and Craigslist), the prices posted online on Craigslist were higher on average than the other venues, except for massage parlors, with online workers making 47 more dollars per encounter than their offline counterparts (Holt et al. 2016). Furthermore, the provision of unprotected sex in particular could lead to differences in pricing. Elmes et al.(2014), suggest that the rate for unprotected sex is on average higher than protected sex. This study, which examines rate differences of unprotected sex for sex workers in Zimbabwe, observes that clients paid on average 42.9 percent more for unprotected sex (Elmes et al., 2014).

In this article, we analyze a dataset from AdultWork.com, a UK-based online platform that facilitates the advertisement of sex workers to determine drivers behind pricing and popularity in the market for sex work AdultWork. 2019). Our main research question is: What are the determinants of price-setting and popularity in online commercial sex work? AdultWork was established in 2003 and is a platform where individuals pay to establish a profile online to sell sexual services. These services range from "cam services" (e.g. sexual services over live video), to erotic art, to in-person sexual services (AdultWork, 2019). Each seller has a profile that provides information about the services they provide, details about themselves, the pricing of various services (rates), a rating provided by previous buyers of the service, and the number of views on their profile. This data is used to analyze drivers of rates and popularity, while thoroughly exploring the intersections of gender, nationality, and service provision. Popularity and satisfaction are operationalized as the number of views per day on a profile and the number of positive reviews (ratings) per year on a profile. 


\section{Data and Methods}

\section{Data Collection}

Each profile on the AdultWork. com contains information about the worker and the services they provide. While variable across providers, a profile typically includes personal information about the seller (age, gender, orientation, location, race, nationality, body statistics), a free-text component where workers can write more about themselves, a photograph, and a link to contact the seller. In order to collect the data from AdultWork, we scraped raw HTML files of seller profiles from the site and used an Extensible Markup Language (XML) parser in Python called ElementTree to extract features from the profiles. We collected all available fields from the profiles, with the exception of telephone numbers and pictures.

\section{Ethics}

The collection and use of this data is in line with the rules laid out by the Intellectual Property Office of the UK and is justified to be collected and analyzed because it is freely available and public, requiring no log-in (Van Hoorebeek, 2014). Individuals have willingly posted this information publicly. Participants are protected because the findings are only presented in aggregated format, no usernames are collected, and all data is held in an encrypted form. This research has been reviewed and approved by the Central University Research Ethics Committee (CUREC) and Humanities Inter-Divisional Research Ethics Committee (IDREC) at Oxford University. The certification number for the research is: SSH_OII_CIA_19_016.

\section{Data Cleaning}

We started with 33,002 profiles and ended with 11,489 profiles after applying multiple filters. Figure 1 shows the process we went through to select profiles for the study. Sellers that did not offer any in-person services on their profiles were excluded from the analysis. A qualitative inspection of these profiles revealed many of these sellers either had deactivated accounts, were purveyors of erotic art, or provided virtual services (e.g. "cam", or video services). Sellers that provided an hourly rate on their profile were included in the study, and the remaining profiles were excluded. We also excluded workers with implausible information on their profiles such as reporting an age over 100. Finally, we excluded the small number of sellers not reporting a gender, who were part of a couple, or who were outside of the UK.

\section{Variables}

We use profile views as an indicator of worker popularity. Profile views are the number of times a profile is visited, and is populated automatically by the website. We normalize this metric and report views per day to control for profile age.

Rates are determined by the provider, and are a representation of self-perceived attractiveness in the market. Each seller provided a maximum of 16 rates for in-calls and out-calls for different durations of service. The durations of service are "15 minutes", "30 minutes", "1 Hour", "1.5 Hours", "2 Hours", "3 Hours", "4 Hours", and "Overnight". "In-call" refers to the scenario in which the client goes to the sex worker's place of residence or work. Conversely,

"out-call" indicates a situation in which the sex worker travels to a specified location outside their place of work (Griffith, Capiola, Balotti, Hart, \& Turner, 2016). 


\section{PROFILE SELECTION PROCESS}

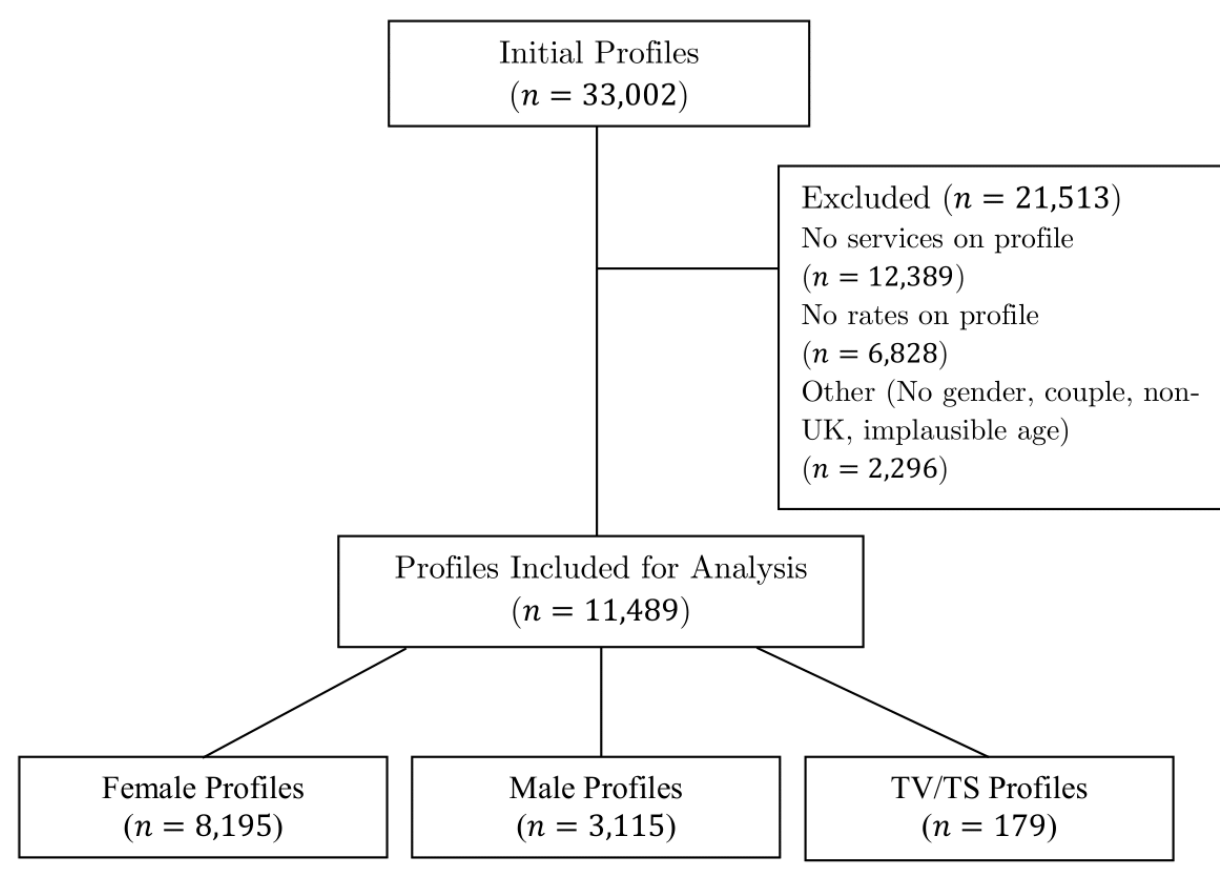

Figure 1: Profile selection procedure.

Ratings: Buyers are given the option to leave feedback on a service after a transaction and receive feedback in return from the sex worker. A buyer's feedback can be positive, neutral, negative or a dispute. Negative ratings and disputes on the platform are used primarily to flag serious issues with the provider. Over 98 percent of ratings on AdultWork are positive. For the purposes of this study, we use positive ratings as a proxy of successful transactions completed with a level of satisfaction that led to a positive review. We consider the number of positive ratings per year to control for profile age.

In addition, we selected nationality, gender, time active on the website, age, region, orientation, dress size, and the services offered as primary independent variables. A summary of the variables is shown in Table 1

\section{Service Provision}

Providing a description of services provided is compulsory for sellers on the platform and is visible on all profiles included in the study. 90 different services are offered across the platform, ranging from a variety of offerings that occurred on nearly every profile to services that rarely occur in the data. The most common services on the platform include practices that appear on more than 10,000 of the profiles (e.g. massage and oral). The least common services provided appeared on as few as 8 profiles (e.g. hardsports). 
Table 1: Variables and Definitions

\begin{tabular}{lll} 
Variables & Definition & Possible Values \\
\hline 1 Hour IC & 1 Hour In-Call Rate & Continuous \\
Views & Profile Views Per Day & Continuous \\
Ratings & Positive Ratings Per Year & Continuous \\
Gender & Male or Female & 2 \\
Nationality & Grouped Nationality & 9 \\
Ethnicity & White, Non-White & 2 \\
Age & Current Age of Worker & Continuous \\
Region & London/Southeast and Other UK & 2 \\
Orientation & Straight, Bisexual, Gay, Not Specified & 4 \\
Unprotected & Offering "Bareback" or "Unprotected Sex" Service $(0$ or 1$)$ & 2 \\
Dress Size & Grouped Ordinal Sizes & 3 \\
\hline
\end{tabular}

\section{Clustering services}

Building from the hypothesis that some services commonly appear on profiles together, we developed a method to group services into categories. We began with a matrix $A$ of the dimensions $n \times m$ where $n=11,489$ is every worker in the dataset and $m=90$ is the number of services offered on the platform. The vector of services, $a_{i j}$, takes on values of 0 or 1 depending whether or not each service appears on a worker's profile. Subsequently, we used the following expression to compute the cosine similarity between service column vector $a_{i}$ and $a_{j}$ and created another adjacency matrix, $B$, of $m$ by $m$ dimensions:

$$
\cos \left(\mathbf{a}_{\mathbf{i}}, \mathbf{a}_{\mathbf{j}}\right)=\frac{\mathbf{a}_{\mathbf{i}} \cdot \mathbf{a}_{\mathbf{j}}}{\left\|\mathbf{a}_{\mathbf{i}}\right\|\left\|\mathbf{a}_{\mathbf{j}}\right\|}=\frac{\sum_{k=1}^{n} a_{i k} a_{j_{k}}}{\sqrt{\sum_{k=1}^{n} a_{i k}^{2} \cdot \sum_{k=1}^{n} a_{j k}^{2}}}
$$

Higher cosine similarity between services suggests that these services more frequently appear on profiles together controlling for their own frequency of appearance. Using the cosine similarity adjacency matrix, $B$, we created a network with nodes consisting of sexual services and edges consisting of the cosine similarity between services. We eliminated self-loops from the analysis and used the Louvain community detection method (Blondel, Guillaume, Lambiotte, \& Lefebvre, 2008), to find communities in the services.

The algorithm yielded four different communities. We refer to these as categories $A-D$. The services not included in any community are considered in a separate category $E$. Figure 2 contains a visualization of the network of services, with different colors representing different communities.

Qualitative inspection of the network suggests $A$ contains services that exist in most profiles, like massage and oral sex ("common services"). $B$ contains more social and collective acts. These include services like swinging, parties, and moresomes ("group/ public services"). $C$ overlaps somewhat with A and B, and contains mostly BDSM-related services. $D$ encompasses increasingly more niche services (ex: enema, rimming, snowballing) ("niche services"). Finally, $E$ constitutes even rarer services that do not belong to any one community, but highly overlap with each other (unprotected sex and period play). Notable in this category is the explicit offering of unprotected sex. 


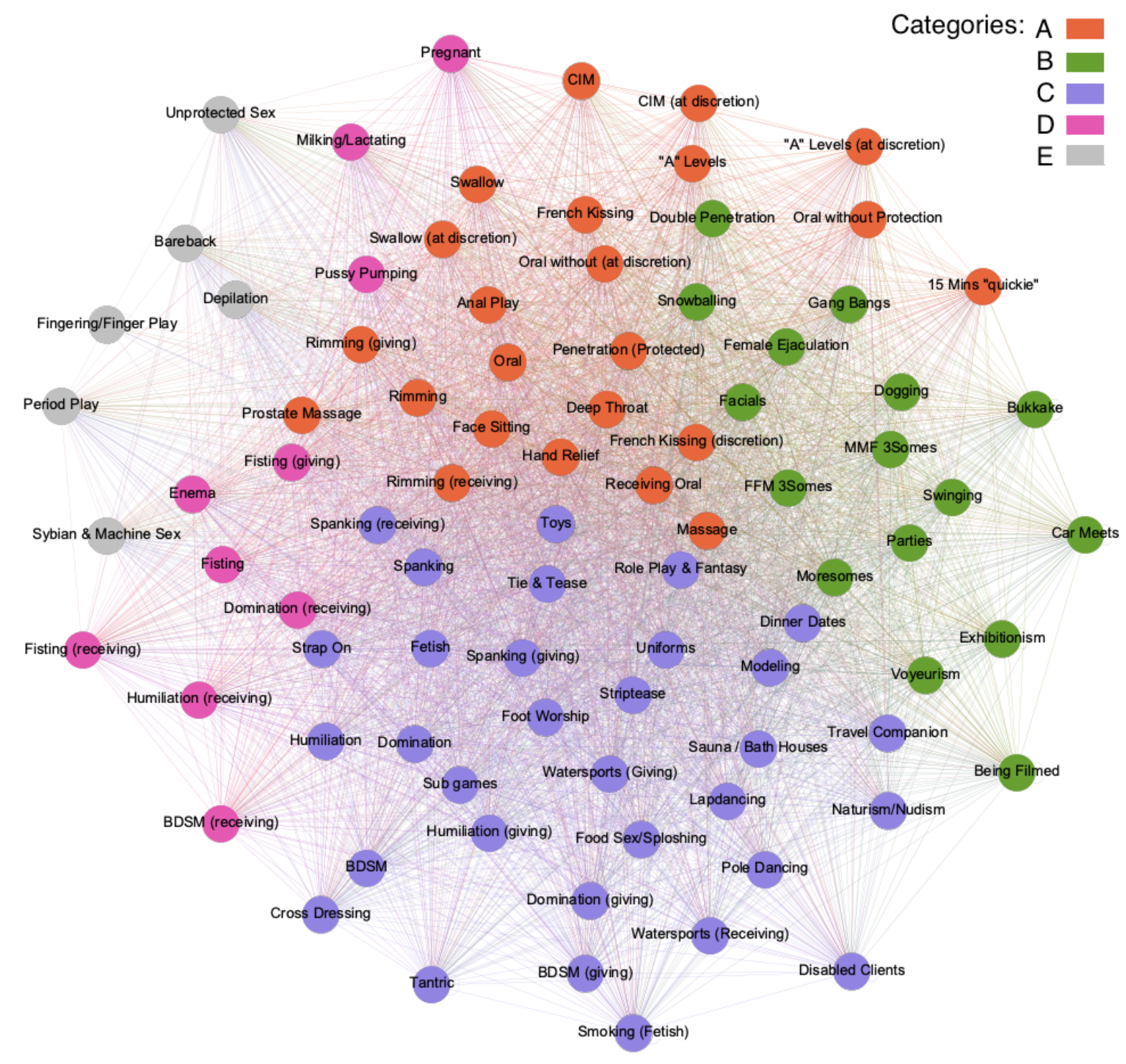

Figure 2: Network of services provided connected by cosine similarity of the list of profiles that the each service is provided on. Colours code the communities that are detected using the Louvain algorithm.

To understand the degree to which workers provide services from each category, we compared each worker's vector of services to each community's basis vector. As the vectors are orthogonal and no one service is present in more than one category, this method created five different scores for each different worker that quantifies the similarity between the set of services they provide and the services in each of the categories $A-E$. Different services and the number of workers that offer them can be seen in Figure 8 of Appendix. 


\section{Results}

\section{Exploratory Analysis}

\section{Gender}

Individuals on AdultWork are divided into the categories: female, male, and TV/TS. On AdultWork, the gender breakdown is 71.3 percent female, 27.1 percent male, and 1.6 percent TV/TS. We report findings separately for male and female populations due to the stark differences between these populations in the data. The distribution of rates, view, and ratings varies dramatically between males and females. Trans-identifying sellers are left out of our statistical analysis, however, it is notable that while estimates of TV/TS in the UK range from 200-400,000 individuals, 0.3-0.6\% of the population (Government Equalities Office, 2018), the fraction of trans-identifying individuals on AdultWork is 1.5 percent of the total population.

\section{Views, Rates, Ratings and time active on platform}

The number of profile views is a significant metric for sellers as the "top of the sales funnel". Buyers need to view a profile in order to know their availability, contact them, complete a transaction, and potentially leave a rating. The distribution of views per day can be seen in Figure 3 (a). Views roughly follow a log-normal distribution with two modes for male and female profiles and with a lower limit for men. The median number of views per day for a female seller on AdultWork is 296.4, and the male sellers have a median of 2.6 views per day.

The hourly rates on the platform are determined by the provider's incentive to stay competitive in a market in which the rates of other providers are visible. Sellers may also set rates to signal quality or vertically segment themselves in the market (Cunningham \& Kendall, 2016). Figure 3.b) shows the distribution of the 1 hour in-call rate in the males and females sub-populations in GBP. Note the logarithmic scale, which suggest a fat-tail for the distribution with very wide range of rates within each sub-populations. The median price of 1 Hour In-Calls is 120 GBP for female workers and 70 GBP for male workers. This finding is notable, especially in light of UK statistics reporting that the average price of an encounter with a sex worker is 78 GBP (UK Home Affairs Committee, 2017). Sellers can provide up to 16 rates on their profiles, with eight different durations and separate categories for in and out-calls.

Although the number of positive ratings is not a perfect proxy for total transactions, as buyers do not always leave reviews, we use ratings to understand a seller's minimum number of satisfactory transactions per year. Ratings are also log-distributed, with 15 percent of all profiles with zero ratings $(n=1,723)$. The distribution of annual ratings (excluding profiles with no ratings) can be seen in Figure 3 (c). The median male worker had 0.62 ratings per year, and median female worker had 7.6 ratings per year.

Sellers on AdultWork have profiles of different ages on the platform. We calculated the amount of time active on the platform by the amount of time between last log-in and the date of profile creation. Figure 3(d) shows the distribution of active years on the platform. Most of the sellers on the platform have approximately 2-3 years of activity. The median length of active time on the platform is 3.7 years. The maximum length of activity is 16 years. As AdultWork was founded in 2003, this indicates that a small number of individuals have been active on the site since near the time of its founding. The measurement of the time active on AdultWork is used primarily to normalize count variables (views, ratings) across profiles. 

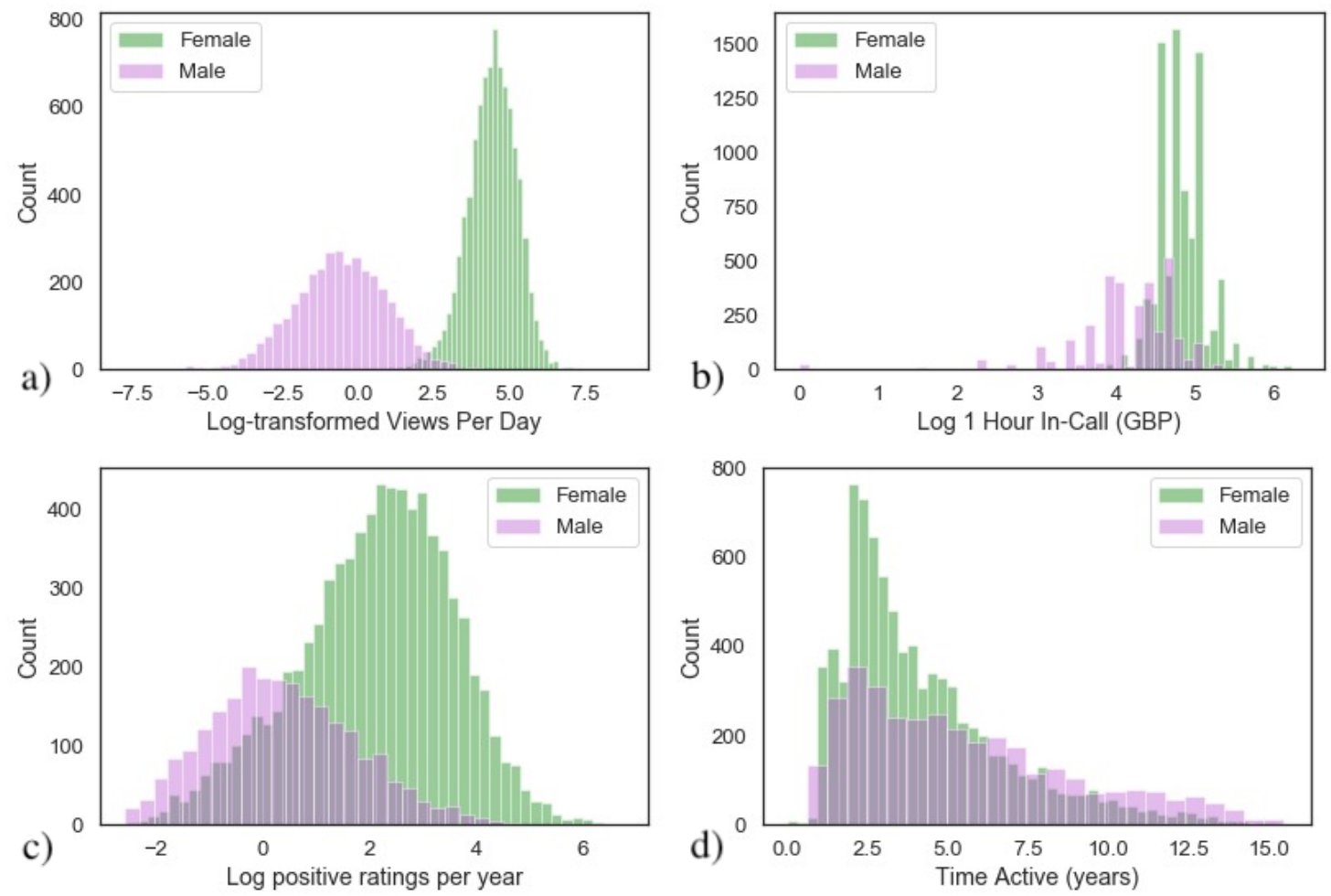

Figure 3: Distributions of a) daily profile views, b) hourly in-call rates, c) the number of positive ratings received per year, and d) the time active on platform. The variables in $(a, b, c)$ are logarithmically transformed.

Figure $4(a-b)$ shows the frequency of service durations provided on the profiles. One hour in-call is the most popular service by sellers. The least frequent duration observed in the data across in and out-calls is 15 minutes, indicating a possible minimum time threshold in which it is worth it for a seller to provide services. Moreover, workers were more likely to offer durations shorter than an hour for in-calls than for out-calls. This could indicate greater opportunity cost on behalf of the seller when they have to travel to meet a client. Similarly, lower hourly rates are observed with longer services. The decreasing median hourly rate over time can be seen in Figure 4(c). In-call and out-call rates are linearly related $4(\mathrm{~d})$ ). However, out-calls are consistently more expensive than in-calls, with the median out-call 1.26 times larger than the in-call on average. The finding that out-calls are consistently more expensive than in-calls is corroborated by past research conducted on the advertisements of US sex workers (Griffith et al. 2016).

\section{Nationality, Age, and Dress size}

Some sex workers choose to report their nationality on their AdultWork profile. As this is not a compulsory data field, only $14 \%$ of males and $64 \%$ of females provide their nationality on their profile. Among those who provide a nationality, 93\% of males are "British". Females have a much more diverse distribution of nationalities with $65 \%$ "British" followed by "Romanian", "Hungarian", "Brazilian", "Czech", "Polish", "Thai", and "Spanish" (see: Appendix Figure 9 for the number of providers reporting these nationalities). Individual nationalities were grouped into 9 larger regions. These regions are Britain, Eastern Europe, Western Europe, Asia, Central/South America, Africa, North America, Oceania, and the Middle East. The nationalities that comprise these larger groupings can be seen in Table 5 in the Appendix. The counts of female workers by nationality can be see in in Figure 5 (a). 

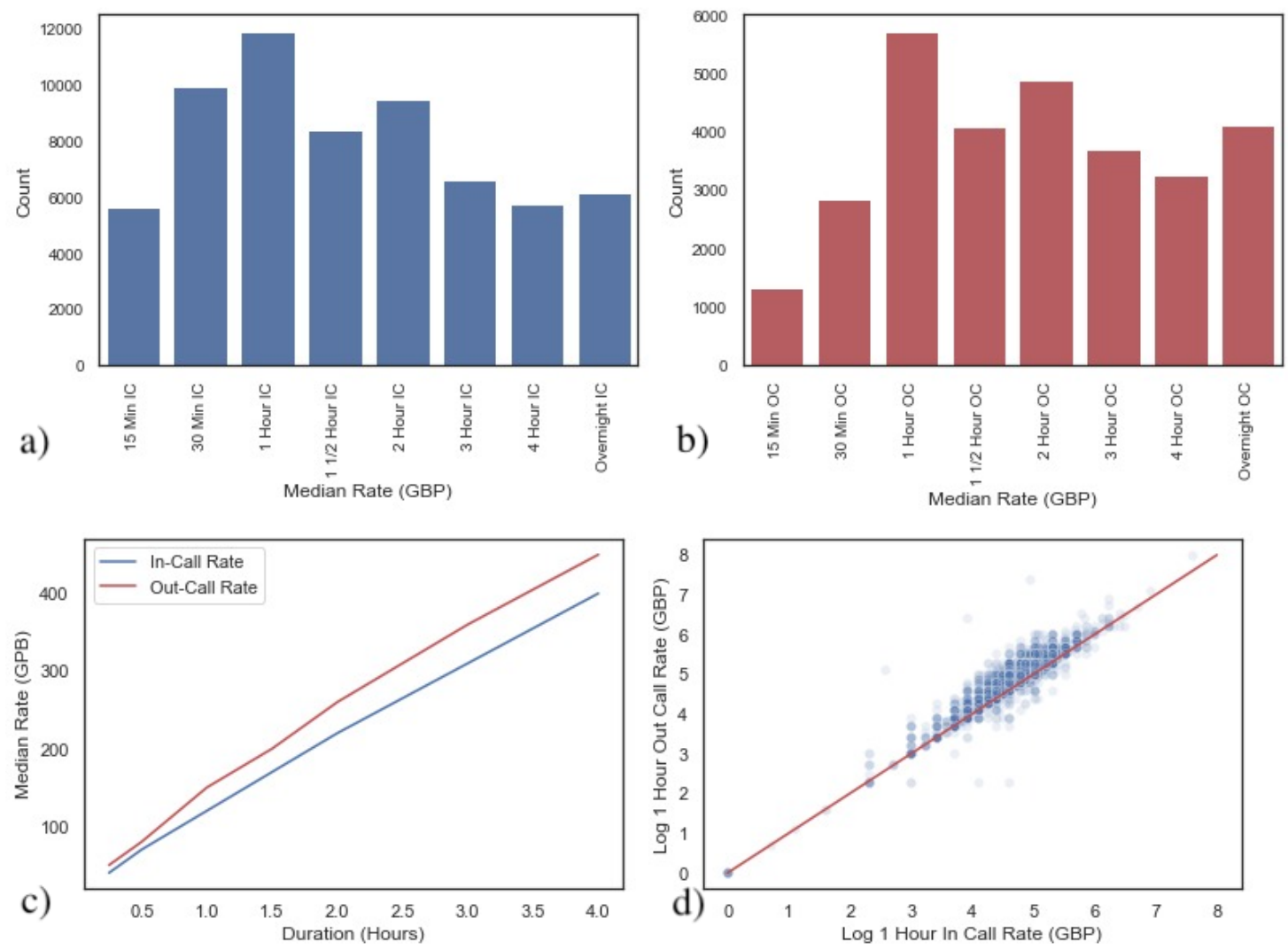

Figure 4: Count of profiles with a set value rate for different durations of service a) in-calls and b) out-calls. c) Median rate over duration of service. d) Comparison of in-calls and out-calls.

The distributions of views, rates, and ratings are detailed in Figure 5 (b-d) for different nationality groups. While garnering slightly higher median number of views on (408 per day vs. 256 a day), female Eastern European sellers had fewer positive ratings than their British counterparts, with 5.7 positive ratings per year versus the British sellers, with 9.2 positive ratings per year. This implies that while Eastern European sellers are getting equal or even more browsing attention than British sellers, the conversion to transactions are lower. More notably, workers of Eastern European nationality have significantly lower average hourly rate than their British counterparts. The median 1 Hour In-Call price for female British sex workers was $130 \mathrm{GBP}$, which is $10 \mathrm{GBP}$ more expensive than the overall female population (120 GBP). In comparison, female Eastern European sellers had median 1 Hour In-Call rate of 100 GPB (30\% less than British). As nationality is impossible to verify, there could be incentives for sellers to be omit or misreport their nationality. This is especially plausible given the large price difference between providers. Correction of such biases would only amplify the reported effects.

Age is a required field on the platform in which sellers report their current age. The AdultWork platform buckets sellers into eight ordinal categories on their search bar; the count of workers in each age group can be seen in Figure 6(a). The median age for men on the platform is 35 years old and the median age for women is 32 years old, with 27 being the most frequently reported age. The dependency of views, rate, and ratings on age is shown in Figure 6 b-d). For women, there is a penalty in rates and views, and ratings to for moving up an age category. This relationship is initially less clear for male workers. We also calculated the age at which the sellers have joined the platform by 

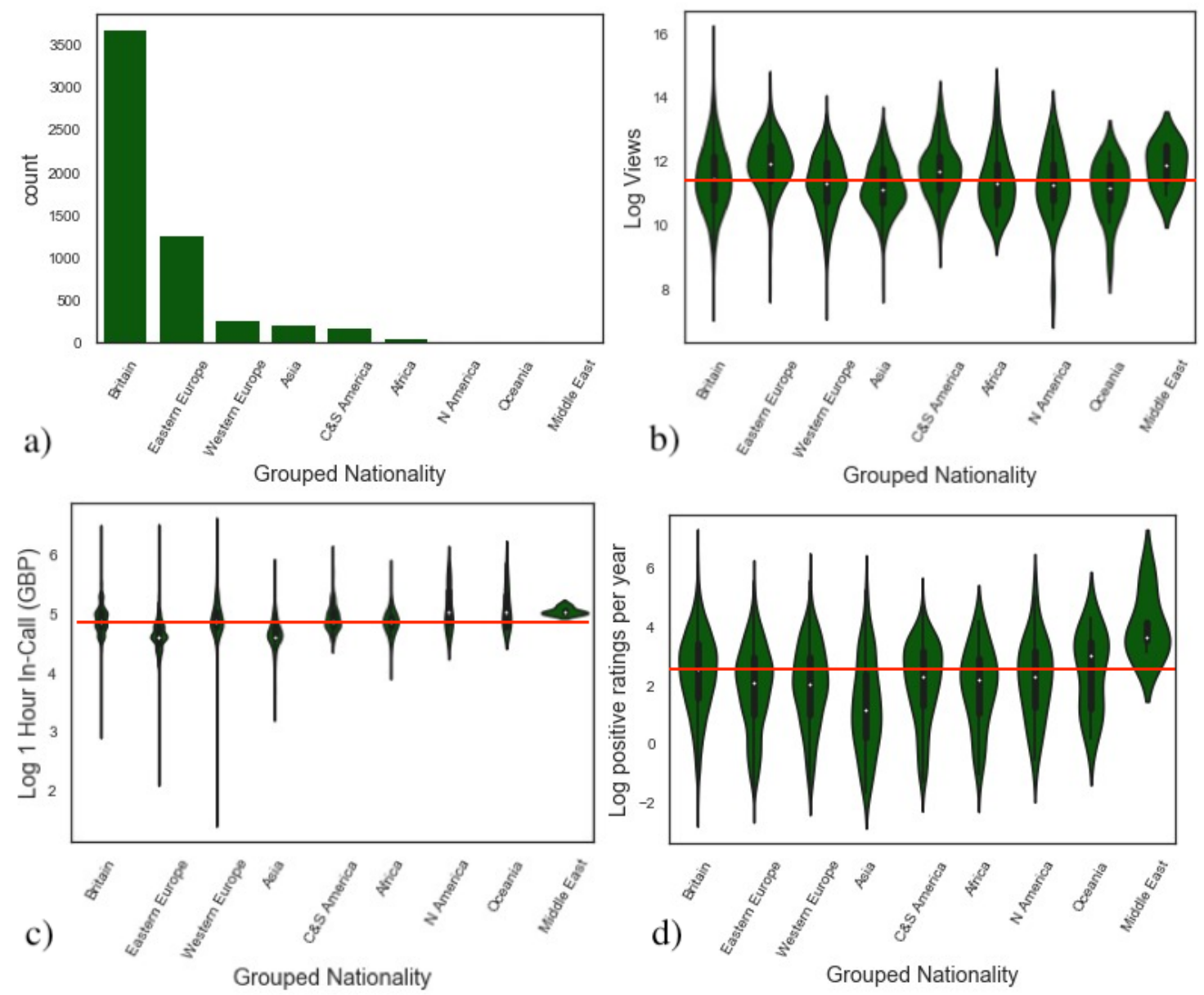

Figure 5: a) Grouped nationality counts. b) Distribution of b) views, c) rates, and d) ratings by nationality.

subtracting the profile age from the current age of the sellers. The distribution of age of joining is shown in Appendix Figure 10 The distribution peaks around 22 for female and 25 for male sex workers.

Dress size is optionally reported. $73 \%$ of females have reported a dress size, whereas less than $1 \%$ of males did so. Hence, we only consider the female workers dress size. The most frequent dress size reported on the platform was a UK 10 (see Figure 7 a); for comparison, the average dress size of 16-24 year-old women in the UK in 2016 was a 14 (Claire Bates, 2016). As shown in Figure 7(b-d) views, rates, and ratings all decrease as the size increases.

\section{Region, Orientation, Ethnicity}

Region is another optional field for sellers and contained missing data (56\% reported region). Workers who reported their regions are concentrated in London (20\%) and the Southeast (35\%). Exploratory analysis on the regions revealed that the largest difference in rates occurred between London and the Southeast, and other regions of the UK. Due to this we divided the regions into two groupings: London and the Southeast, and Other UK. The detailed count sex workers in the regions before grouping is in the Appendix Figure 11 a). Sex workers in London and the Southeast had a higher hourly in-call than their counterparts in other parts of the UK but the difference in ratings is opposite and the workers in othe parts of the UK recieve more ratings. The profile views per day is almost independent of region. Female workers 

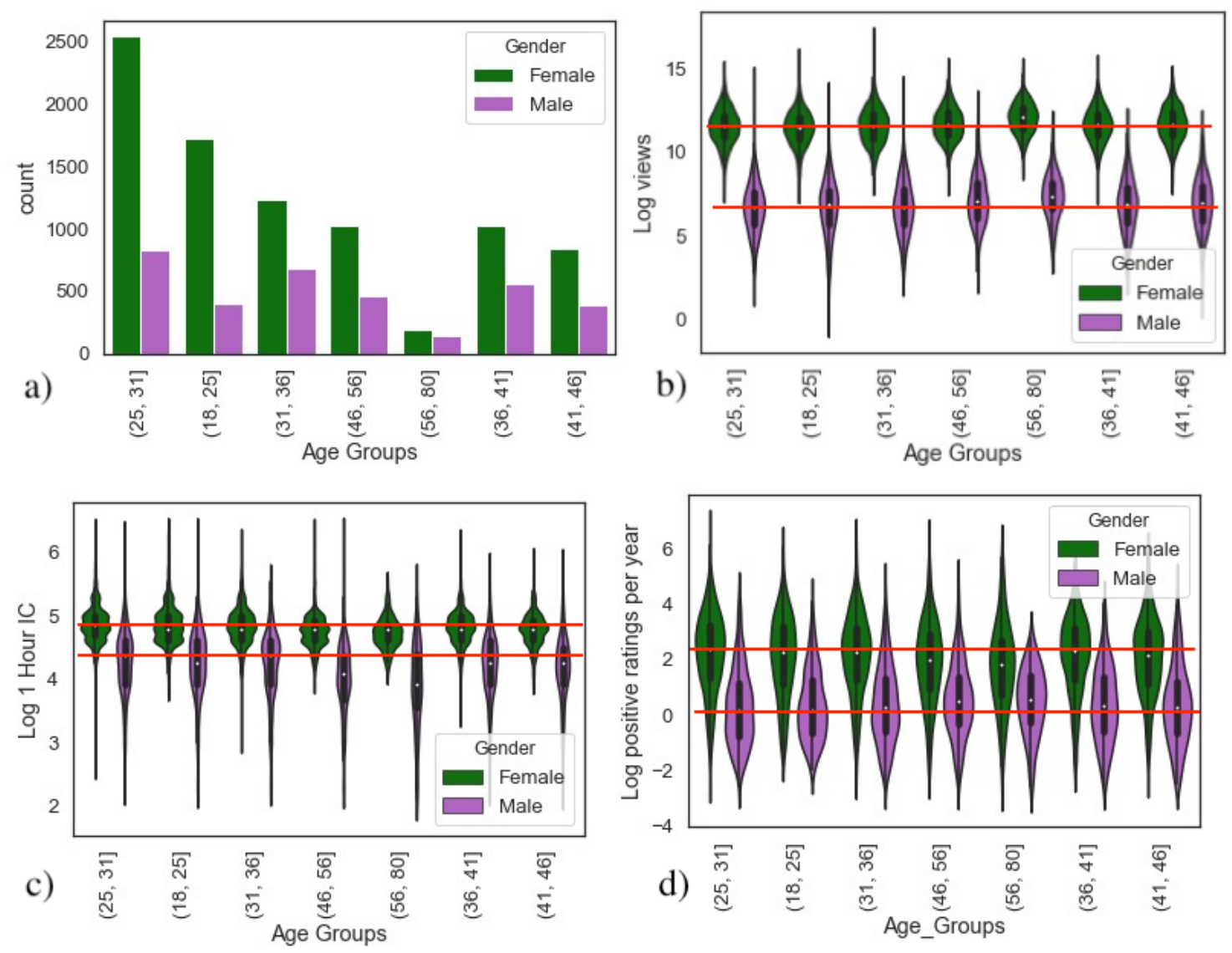

Figure 6: a) Counts of workers by age group. b) views, c)rates, and d) ratings for different age groups.

in the London and the Southeast (other places in the UK) had a median views per day of 305(304), median rate of 130(120) GBP, and median ratings per year of 7.2(8.4), and male workers had a median views per day of 3(2.4), median rate of 80(70) GBP, and median ratings per year of 0.66(2.74); see Appendix Figure11. (c-d).

The ethnicity of 50 percent of sellers on the platform is self-reported as white with 21.2 percent missing entries and roughly 21.8 percent reporting as non-white (see Appendix Figure 12 for more detail). Ethnicity is forced into categories by the platform. Non-white sellers report as majority mixed, Black or Asian. The large number of missing entries could be in part due to the platform affordances. It is evident that at least for female workers being "non-white" brings less views, lower hourly rate, and fewer positive ratings.

The orientation of $57.3 \%$ of sellers is self-identified as bi-sexual or bi-curious, with $41.9 \%$ identifying as straight, and less than 1 percent identifying as gay. The large number of bi-identifying individuals in the data could be advantageous from perspective of sellers attempting to reach as wide of an audience of prospective buyers as possible. Sellers advertising as bisexual or bi-curious receive a modest boost to popularity and rates on average in comparison to other orientations (see Appendix Figure 13). 

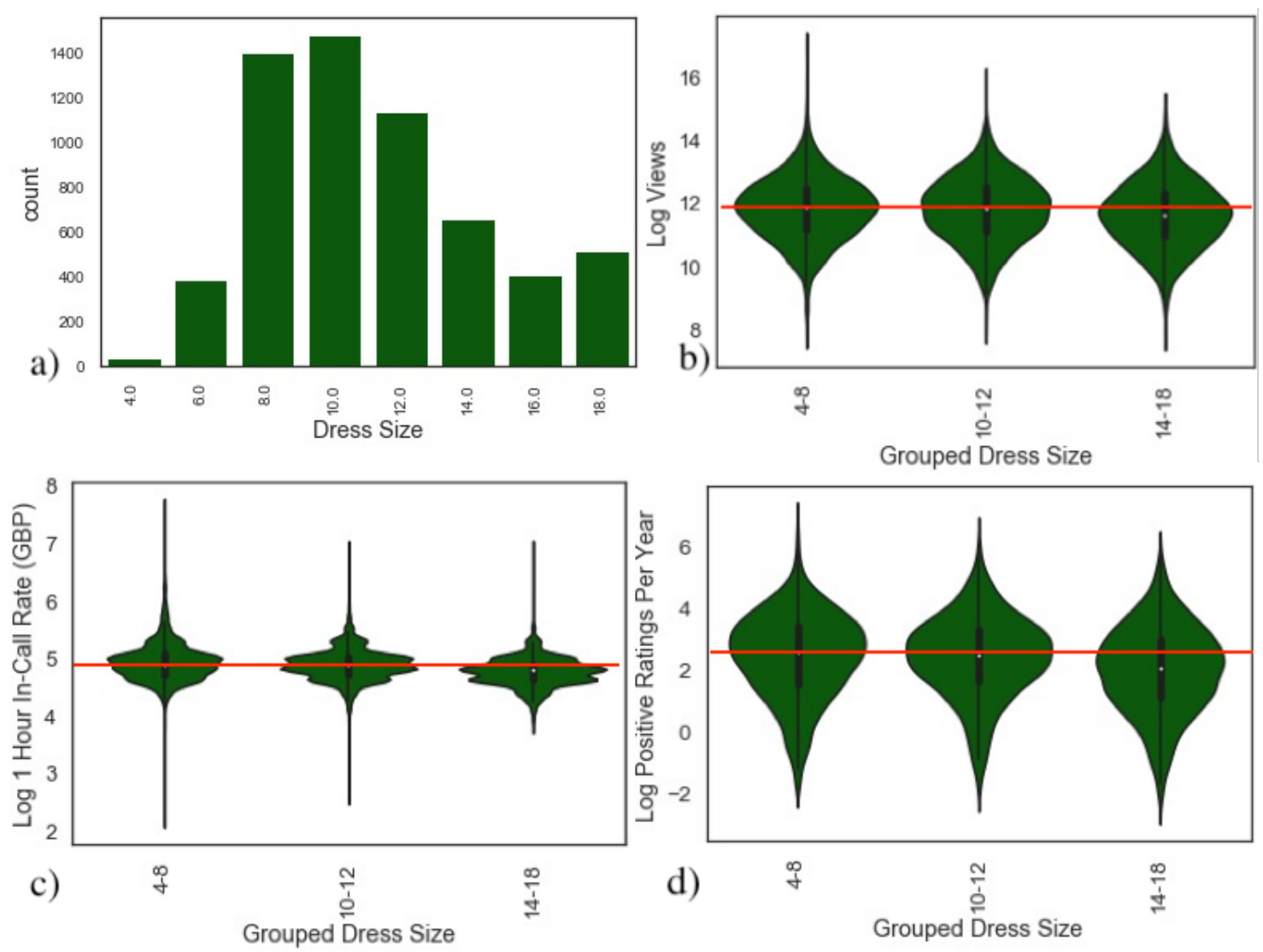

Figure 7: a) Dress sizes count. Dress Size and b) views per day, c) rate, and d) ratings.

\section{Regression Results}

We ran regressions to model, views per day, hourly rate, and ratings per year of workers by gender sub-population. The reader should be reminded that these three variables are proxies for initial attractiveness to buyers, self-assessed price by sellers, and satisfaction by buyers after transaction. Considering the shape of distribution of these variables, shown in Figure 3, we used logarithmically transformed values of them in our regression analysis.

\section{Female Workers}

In analysing the female sellers on the platform the baseline comparison groups for binary variables are British nationality, white ethnicity, dress size 4-8, and straight orientation. The regression results are presented in Table 2

Notable among the regression results are the negative effects of age on hourly rate despite its positive effect on the number of satisfied buyers (positive ratings). The former has been seen in previous literature for female sex workers (Dunn, 2018). Ethnicity plays an important negative role on viewership and post-transaction satisfaction, whereas it has no significant effect on the hourly rate. This finding is in agreement with prior literature that finds that buyers demonstrate racial bias in selecting sex workers (Holt et al., 2016, Robinson, 2015).

Female workers are heavily penalized on their dress size, however the negative effect on hourly rates, that are self-selected is larger than on viewership. There is no significant effect on buyers' satisfaction. Nationality however 
Table 2: Regression Results for Female Workers

\begin{tabular}{|c|c|c|c|c|}
\hline & & Views per day & Log 1 Hour In-call(£) & Positive ratings per year \\
\hline Age & & $-0.208(-1.47)$ & $-0.00359^{* * *}(-10.26)$ & $0.165^{* * *}(3.73)$ \\
\hline \multirow{2}{*}{$\begin{array}{l}\text { Ethnicity } \\
\text { (baseline: White) }\end{array}$} & Non-White & $-13.54^{* * *}(-3.35)$ & $-0.00254(-0.26)$ & $-8.392^{* * *}(-9.28)$ \\
\hline & Missing & $-32.49^{*}(-2.01)$ & $-0.0214(-1.39)$ & $-3.572^{*}(-2.12)$ \\
\hline \multirow{3}{*}{$\begin{array}{l}\text { Dress size } \\
\text { (baseline: } 4-8 \text { ) }\end{array}$} & $10-12$ & $-15.35^{* *}(-3.09)$ & $-0.0619^{* * *}(-6.99)$ & $-0.733(-0.60)$ \\
\hline & $14-18$ & $-37.89^{* * *}(-6.39)$ & $-0.156^{* * *}(-15.34)$ & $-3.443^{*}(-2.45)$ \\
\hline & Missing & $-14.63(-0.84)$ & $-0.0986^{* * *}(-6.08)$ & $-6.146^{* *}(-2.89)$ \\
\hline \multirow{9}{*}{$\begin{array}{l}\text { Nationality } \\
\text { (baseline: British) }\end{array}$} & Eastern Europe & $37.71^{* * *}(8.12)$ & $-0.308^{* * *}(-31.60)$ & $-9.529 * * *(-6.91)$ \\
\hline & S./C. America & $32.35^{* * *}(3.81)$ & $-0.0476^{*}(-2.57)$ & $-7.904^{* * *}(-5.29)$ \\
\hline & Asia & $-2.450(-0.47)$ & $-0.229^{* * *}(-11.48)$ & $-1.931(-1.26)$ \\
\hline & Western Europe & $-1.320(-0.21)$ & $-0.0612^{*}(-2.51)$ & $-5.282^{* * *}(-3.32)$ \\
\hline & North America & $-26.59^{* *}(-2.66)$ & $0.0758(1.16)$ & $-3.186(-0.53)$ \\
\hline & Africa & $-10.63(-1.02)$ & $-0.0781^{*}(-2.50)$ & $-3.434(-1.88)$ \\
\hline & Oceania & $-16.46(-1.10)$ & $0.113^{*}(2.45)$ & $-0.945(-0.25)$ \\
\hline & Middle East & $11.89(0.50)$ & $0.0547(1.38)$ & $55.41(1.16)$ \\
\hline & Missing & $-19.18^{* * *}(-5.97)$ & $-0.0841^{* * *}(-11.64)$ & $-5.391^{* * *}(-5.94)$ \\
\hline Number of Services & & $3.107 *(2.48)$ & $-0.00901^{* * *}(-6.29)$ & $0.604^{* * *}(4.30)$ \\
\hline \multirow[t]{5}{*}{ Service Category } & A & $8.271(0.18)$ & $0.367^{* * *}(5.15)$ & $-30.89^{* * *}(-4.25)$ \\
\hline & $\mathrm{B}$ & $-122.7^{*}(-2.21)$ & $0.452^{* * *}(6.64)$ & $-21.06^{* * *}(-3.44)$ \\
\hline & $\mathrm{C}$ & $-116.4(-1.87)$ & $0.777^{* * *}(9.18)$ & $-24.68^{* *}(-2.97)$ \\
\hline & $\mathrm{D}$ & $-82.93(-1.38)$ & $0.460^{* * *}(5.97)$ & $-20.78^{* *}(-2.82)$ \\
\hline & $\mathrm{E}$ & $71.75(0.85)$ & $0.119(1.13)$ & $-20.91(-1.75)$ \\
\hline \multirow{2}{*}{$\begin{array}{l}\text { Orientation } \\
\text { (baseline: Straight) }\end{array}$} & Bisexual & $-0.631(-0.22)$ & $0.0451^{* * *}(6.71)$ & $1.673^{*}(2.42)$ \\
\hline & Gay & $-29.12(-1.36)$ & $0.173(0.50)$ & $3.238(0.84)$ \\
\hline London \& Southeast & & $-0.952(-0.32)$ & $0.107^{* * *}(15.95)$ & $-2.297^{* *}(-2.80)$ \\
\hline Views per day & & & & $0.100^{* * *}(4.44)$ \\
\hline Log 1 Hour In-call(£) & & & & $11.75^{* * *}(4.96)$ \\
\hline Constant & & $120.6^{* * *}(4.79)$ & $4.808^{* * *}(107.72)$ & $-39.17^{* *}(-3.23)$ \\
\hline Observations & & 8195 & 7990 & 7990 \\
\hline Adjusted $R^{2}$ & & 0.078 & 0.258 & 0.207 \\
\hline
\end{tabular}

$t$ statistics in parentheses

${ }^{*} p<0.05,{ }^{* *} p<0.01,{ }^{* * *} p<0.001$

plays the most important role in determining the hourly rate. For majority of non-British nationalities, the rates are lower compared to workers with British nationality. The largest decrease in hourly rate are imposed on workers from the East European and Asian countries followed by South and Central Americans. Interestingly, East European profiles have much higher viewership compared to any other nationality, but with the lowest number of positive ratings. The same pattern is observed for South and Central American workers, but with smaller magnitudes. A missing nationality is associated with a decrease in all the three dependent variables.

After controlling for the total number of services provided, we see female workers offering category C ("BDSM services"), category B (collective or external-facing services such as dinner dates and threesomes), and category D ("niche services") charge higher hourly rates. It is possible that sex workers that have more services in this category could be vertically differentiating themselves by providing "girlfriend/pornstar experience"-type services (Cameron, 
2016). The variations in pageviews and positive ratings between service groups are small, however the least amount of positive reviews are coming with the basic services (Category A).

Providing services in the Southeast and London is associated with higher rates on average than workers providing services out of London and the Southeast. This could be reflective of economic differences between London and the Southeast and other areas of the UK (Office for National Statistics, 2019). Finally, identifying as bisexual (versus a baseline of straight) is associated with a modest boost to hourly rate on average. Finally, both viewership and hourly rate show a significant positive relation with the number of positive ratings. This means that buyers who paid higher rates are more likely to leave a positive rating.

\section{Male Workers}

We ran a similar regression model for male workers (without the Dress Size variable). The full results are shown in Table 3.

Table 3: Regression Results for Male Workers

\begin{tabular}{|c|c|c|c|c|}
\hline & & Views per day & Log 1 Hour In-call(£) & Positive ratings per year \\
\hline Age & & $-0.0197(-0.63)$ & $-0.0175^{* * *}(-4.03)$ & $0.0629^{* * *}(4.82)$ \\
\hline \multirow{2}{*}{$\begin{array}{l}\text { Ethnicity } \\
\text { (baseline: White) }\end{array}$} & Non-white & $0.703(0.62)$ & $0.0863(0.86)$ & $0.432(0.68)$ \\
\hline & Missing & $-1.017(-1.83)$ & $-0.155(-1.20)$ & $0.0388(0.14)$ \\
\hline \multirow{9}{*}{$\begin{array}{l}\text { Nationality } \\
\text { (baseline: British) }\end{array}$} & Middle_East & $-3.665^{*}(-2.24)$ & $0()$. & $-3.572^{* * *}(-4.73)$ \\
\hline & North America & $-3.187^{* *}(-2.86)$ & $0()$. & $-1.522 *(-2.55)$ \\
\hline & S./C. America & $-4.396^{*}(-2.50)$ & $-0.795^{* * *}(-4.82)$ & $-2.819^{*}(-2.32)$ \\
\hline & Asia & $-4.686^{*}(-2.37)$ & $0()$. & $-3.176^{* *}(-3.22)$ \\
\hline & Africa & $-1.466(-0.59)$ & $0.281^{*}(2.04)$ & $-1.746(-1.07)$ \\
\hline & Eastern Europe & $-2.556(-1.26)$ & $-0.205(-1.89)$ & $-1.799(-1.36)$ \\
\hline & Western Europe & $-3.371(-1.55)$ & $0.0934(0.58)$ & $2.360(0.63)$ \\
\hline & Oceania & $0()$. & $0()$. & $0()$. \\
\hline & Missing & $-4.042^{*}(-2.24)$ & $-0.260^{* * *}(-3.85)$ & $-0.918(-1.86)$ \\
\hline Number of Services & & $0.0312(0.43)$ & $0.0167(1.79)$ & $0.0801(1.70)$ \\
\hline \multirow[t]{5}{*}{ Service Category } & $\mathrm{A}$ & $-1.189(-0.46)$ & $-0.966^{*}(-2.08)$ & $-2.947(-1.32)$ \\
\hline & $\mathrm{B}$ & $2.479(0.82)$ & $-1.007(-1.94)$ & $-2.234(-1.12)$ \\
\hline & $\mathrm{C}$ & $3.891(0.67)$ & $-1.033(-1.45)$ & $-5.403(-1.83)$ \\
\hline & $\mathrm{D}$ & $-5.083^{*}(-2.08)$ & $-0.662(-1.26)$ & $-0.646(-0.22)$ \\
\hline & $\mathrm{E}$ & $1.693(0.31)$ & $0.562(0.65)$ & $-6.839^{*}(-2.25)$ \\
\hline Orientation & Bisexual & $0.832(1.24)$ & $0.00645(0.06)$ & $-0.209(-0.71)$ \\
\hline (baseline: Straight) & Gay & $2.230(1.80)$ & $0.211(1.57)$ & $-2.079^{* * *}(-7.97)$ \\
\hline London \& Southeast & & $-0.155(-0.31)$ & $0.163^{*}(2.16)$ & $0.695^{*}(2.33)$ \\
\hline Views per day & & & & $0.0270^{* *}(3.13)$ \\
\hline Log 1 Hour In-call(£) & & & & $0.703^{* *}(2.85)$ \\
\hline Constant & & $5.143^{* *}(2.63)$ & $5.917^{* * *}(12.34)$ & $0.0262(0.02)$ \\
\hline Observations & & 3115 & 2119 & 2964 \\
\hline Adjusted $R^{2}$ & & 0.011 & 0.150 & 0.018 \\
\hline
\end{tabular}

Generally, we observe less explanatory power in the selected variables for male workers. This suggest that the role of demographic and physical attributes in popularity and hourly rate of sellers is less important when it comes to 
male workers. Nevertheless, similar to female workers, older male sellers charge lower hourly in-call rates. However, there is a significant positive effect from age on the number of positive ratings. Dissimilar to female workers, ethnicity plays no role in the case of male workers.

The most notable nationality effect comes in the case of Central/South American workers with significant lower hourly rates than British workers. There are much fewer positive ratings for workers from the Middle East and Asia. However, one should remember that the male population in the sample is predominantly British and the reported results might not be easily generalised to a more balanced population. As for the service prevision, male workers that provide more "A", or common services, tend to charge a lower hourly rate. The regional trend of offering lower hourly rates in regions of the UK other than London and the Southeast continues with male sellers. For male workers too, higher page views and higher hourly rates associate to larger number of positive ratings.

It is worth noting that the selection advantage of identifying as bisexual for female workers disappears in the male population, of which 62 percent is straight-identifying. In fact, identifying as having a gay orientation is associated with significantly smaller number of positive ratings than the straight baseline for men. The large number of men that identify as straight on the platform may indicate an underestimation of women who buy sex, in the literature.

\section{Unprotected Sex}

Our dataset presents a unique opportunity to analyze the provision of unprotected sex. The provision of "bareback", or unprotected sex, has ramifications for pricing of sexual services (Cunningham \& Kendall, 2016, Elmes et al., 2014), and has a strong relationship with lower hourly rates in the dataset. In addition to the implications for rate-setting, we focus on the provision of unprotected sex because it has wider safety and epidemiological applications for workers. 1,304 providers offer either "Bareback" or "Unprotected Sex" or both, constituting 11.35 percent of the sample. While some studies have predicted a higher premium for unprotected sex (Elmes et al., 2014), potentially to compensate for the additional risk undertaken by the seller, others indicate a lower price for sellers that offer unprotected sex or "bareback" (Cunningham \& Kendall, 2016). We find that sellers that offer unprotected sex services tend to charge less expensive 1 hour in-call rates (65 and 110 GBP for men and women) than their counterparts that did not offer this service (70 and 120 GBP for men and women) on average ( $p<.05)$. This corroborates the findings in (Cunningham \& Kendall, 2016), which finds lower rates on average for unprotected sex in a study of a US-based platform, the Erotic Review.

We used a logistic regression to analyse the likelihood of providing bareback or unprotected sex services (see Table 4). The greatest predictor of unprotected sex is identifying as male. Providers from Eastern Europe and younger sellers were also more likely to provide bareback or unprotected sex in comparison to the baseline of British and female

sellers. Finally, being older or non-white is significantly associated with a lower likelihood of providing unprotected sex.

\section{Discussion and Conclusion}

In this study, we found that nationality, age, services offered, ethnicity, region, and orientation influence rates and popularity in the market for commercial sexual services. The influences of these variables are complex and differ dramatically between different genders. While all of the variables in the study add explanatory power to understanding 
Table 4: Logistic Regression for Unprotected Sex

\begin{tabular}{|c|c|c|}
\hline & & Unprotected \\
\hline Age & & $-0.0177^{* * *}(-4.63)$ \\
\hline Gender Male & & $1.537^{* * *}(18.85)$ \\
\hline $\begin{array}{l}\text { Ethnicity } \\
\text { (baseline: White) }\end{array}$ & $\begin{array}{l}\text { Nonwhite } \\
\text { Missing }\end{array}$ & $\begin{array}{l}-0.398^{* * *}(-3.43) \\
0.0937(1.37)\end{array}$ \\
\hline $\begin{array}{l}\text { Nationality } \\
\text { (baseline: British) }\end{array}$ & $\begin{array}{l}\text { Eastern Europe } \\
\text { S./C. America } \\
\text { Western Europe } \\
\text { Asia } \\
\text { Africa } \\
\text { Oceania } \\
\text { North America } \\
\text { Middle East } \\
\text { Missing }\end{array}$ & $\begin{array}{l}0.307^{* *}(2.65) \\
-2.525^{*}(-2.51) \\
-0.891^{*}(-2.44) \\
-1.000^{*}(-2.20) \\
-0.864(-1.21) \\
0.00752(0.01) \\
0(.) \\
0(.) \\
0.0227(0.28)\end{array}$ \\
\hline $\begin{array}{l}\text { Orientation } \\
\text { (baseline: straight) }\end{array}$ & $\begin{array}{l}\text { Bisexual } \\
\text { Gay }\end{array}$ & $\begin{array}{l}0.158^{*}(2.35) \\
0.245(0.81)\end{array}$ \\
\hline London \& Southeast & & $-0.00244(-0.04)$ \\
\hline TV-TS & & 0.445 (1.67) \\
\hline Constant & & $-2.196^{* * *}(-13.81)$ \\
\hline $\begin{array}{l}\text { Observations } \\
t \text { statistics in parenthese } \\
{ }^{*} p<0.05,{ }^{* *} p<0.0\end{array}$ & $p<0.001$ & 11489 \\
\hline
\end{tabular}

the market for sex work, there is much more variability in the data that is left to explain. The findings of this research contribute to an extremely limited empirical literature around sex work. Research on drivers of the market for sex work has implications for understanding sexual preferences, demographics, health risks, and working lives of sex workers, a traditionally stigmatized subset of society.

The unique drivers of rates that we found in this research can help understand the lived experience of sex workers. Building on the work of Bettio et al. (2017), sex workers who offer lower rates are more likely to experience stigma and less agency as being part of the 'lower-end' sexual services market. In particular, for cisgender women in the UK context, Eastern European nationality is strongly associated with both lower rates and lower numbers of positively rated transactions. This finding, along with the result that reporting Eastern European nationality is significantly associated with a higher probability of offering unprotected sex, empirically supports the findings of Platt et al. (2011), a smaller interview-based study which highlights the additional health risks and stigma associated with being a Eastern European migrant sex worker in the UK. Similarly, the divide in sex worker rates between London and the Southeast and other parts of the UK across all genders could signify a higher number of 'lower-end' workers in areas outside of London, or alternatively could just be an reflection of the larger North-South London digital and economic divide in the UK (Office) for National Statistics, 2019).

This research provides greater insight into male sex workers. The findings shed light on the relatively high rate of male sex workers, who have unique drivers of pricing and popularity. Understanding the scope of male and trans-identified sex workers is especially important for the allocation of resources for sex worker safety and educated policy creation around these populations. While prior literature indicates that 85 to 90 percent of all sellers are women, 
this finding corroborates the alternative position, that studies are consistently underestimating the importance and number of men in sex work (UK Home Affairs Committee, 2017).

In addition to understanding the wider themes about sex work by seller rates and demographics, understanding popularity metrics like views and ratings illuminates buyer preferences and biases at a granular level. Because internet platforms allow for buyer anonymity, the clear significance of many sex worker traits and services to selection can illuminate sexual preferences of buyers while mitigating the influence of social mores associated with public dating choices. The results of this research could be of interest to individuals studying human sexuality. This study has revealed that certain sexual services commonly co-occur and can be "bundled together" into roughly five categories, a mapping that is a novel contribution to the literature. Consumers value these categories of sexual services differently, which has consequences for both rates and popularity of sex workers. While female sellers in popularity from providing more BDSM and collective services, male sellers benefit from offering more common and fewer "niche" services. Ultimately, selection based on services offered demonstrates the ability of buyers to exploit the versatility of options online with lower search costs (Cameron, 2016).

Other than website-specific features, the information provided by users is self-reported. Depending on the information and the perceived desirability of the trait, there may be systemic under or over reporting of features on the platform (i.e. if emphasizing one trait is advantageous, sellers may have incentive to highlight that trait). As indicated throughout the study, there are significant advantages to identifying as having British nationality, reporting a younger age, and offering (and not offering) various services. It is worth noting, however, that being untruthful about traits like age that could potentially detected by a buyer could hurt the seller in ratings, future transactions, and potentially subject them to danger (Holt et al., 2016).

External validity is also a concern in the discussion of the market for sex workers. The individuals represented in this data do not necessarily represent the overall population for sex work, and they represent a selected subset of individuals who participate in online sex work environment. Furthermore, the population of sellers on AdultWork are not necessarily representative of in-person sex workers. As indicated in earlier studies, like in Cameron (2016) and in Cunningham, Deangelo, and Tripp Baylor (2019), sex workers who are not online both tend to offer lower rates, may not require references to screen clients, and may be subject to additional health risks.

Further directions that can be taken to enrich the analysis in this study include conducting interviews with workers themselves on the website to understand qualitatively what drives escorts to set their prices and which buyers they are hoping to attract. In particular, more visibility into the safety practices online sellers engage in would add to the literature, especially considering the high granularity of personal data on their profiles. It would be especially useful to gain insight into how the back and forth between buyers and sellers works, and whether sellers screen buyers with "networked screening" as Cunningham et al. (2019) purports that many sex workers do. A further line of analysis could be taking multiple "snapshots" or data collections of the data to determine what conditions cause rates to potentially change, or what drives sellers out of the market. Finally, more analysis could be performed on other forms of sex work present in the website, such as the sales of erotic goods or erotic art, which are forms of sexual commerce online that are rising in popularity (Mowlabocus \& Wood, 2015).

An important aspect of the study that requires further study and attention is the issue of the granularity of the information of escorts online. Personally identifiable details were readily available on the website, including 
phone number and location, often at town-level specificity. The openness of this information presents special risks to potentially underage or trafficked individuals, which could be an important subject of further inquiry. As Jones (2015) notes, while the risks of street-level and outdoor prostitution have been well-studied, there is little information on the unique risks to advertising sex work online.

Finally, this research has implications for entities interested in the spread of STIs and from the perspective of policy-makers who allocate resources to support at-risks populations. Notably, male workers, bisexual workers, young workers and workers of Eastern European nationality have higher probability of providing unprotected sexual services on the platform. As such, these populations may face greater exposure to STIs and health risks. These findings are consistent with Fournet et al. (2016), which finds that young male sex workers who identify as bisexual or gay have a high risk of exposure to STIs.

\section{References}

Adriaenssens, S., Geymonat, G. G., Oso, L., \& Leuven, K. (2016, nov). Quality of Work in Prostitution and Sex Work. Introduction to the Special Section. Sociological Research Online, 21(4), 1-12. Retrieved from http://journals.sagepub.com/doi/10.5153/sro.4165 doi: 10.5153/sro.4165

AdultWork. (2019). AdultWork.com - About Us. Retrieved 2019-08-01, from https://www.adultwork.com/ AboutUs.asp

Balfour, R., \& Allen, J. (2014). A Review of the Literature on Sex Workers and Social Exclusion (Tech. Rep.). UCL Institute of Health Equity. Retrieved from https://assets.publishing .service.gov.uk/government/uploads/system/uploads/attachment\{_\}data/file/303927/

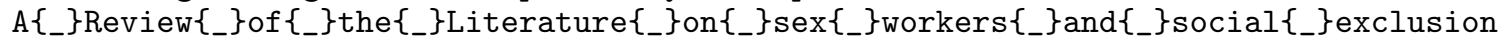
.pdf

Bettio, F., Della Giusta, M., \& Di Tommaso, M. L. (2017, jul). Sex Work and Trafficking: Moving beyond Dichotomies. Feminist Economics, 23(3), 1-22. Retrieved from https://www.tandfonline.com/doi/full/10.1080/ 13545701.2017.1330547 doi: 10.1080/13545701.2017.1330547

Blondel, V. D., Guillaume, J.-L., Lambiotte, R., \& Lefebvre, E. (2008, oct). Fast unfolding of communities in large networks. Journal of Statistical Mechanics: Theory and Experiment, 2008(10), P10008. Retrieved from http://stacks.iop.org/1742-5468/2008/i=10/a=P10008?key=crossref .46968f6ec61eb8f907a760be1c5ace52 doi: 10.1088/1742-5468/2008/10/P10008

Burgess, J., Marwick, A., Poell, T., Bucher, T., \& Helmond, A. (2017). The Affordances of Social Media Platforms. In The sage handbook of social media (pp. 233-253). Retrieved from https://pure.uva.nl/ws/files/ 9115828/BucherHelmond\{_\}SocialMediaAffordances\{_\}preprint.pdf doi: 10.4135/9781473984066 . $\mathrm{n} 14$

Cabral, L., \& Hortaçsu, A. (2010, mar). THE DYNAMICS OF SELLER REPUTATION: EVIDENCE FROM EBAY. The Journal of Industrial Economics, 58(1), 54-78. Retrieved from http://doi.wiley.com/10.1111/ j.1467-6451.2010.00405.x doi: 10.1111/j.1467-6451.2010.00405.x

Cameron, S. (2016). Oxford Handbooks Online Empirical Analysis of the Impact of Legal Status on Versatility and Efficiency in Prostitution Markets (Vol. 1; S. Cunningham \& M. Shah, Eds.) (No. February 2018). Oxford University Press. Retrieved from http://oxfordhandbooks.com/view/10.1093/oxfordhb/ 9780199915248.001.0001/oxf ordhb-9780199915248-e-5 doi: 10.1093/oxfordhb/9780199915248.013.5

Claire Bates. (2016). How does 'Curvy Barbie' compare with an average woman? - BBC News. Retrieved 2019-07-17, from https: //www.bbc.co.uk/news/magazine-35670446

Cunningham, S., Deangelo, G., \& Tripp Baylor, J. (2019). Craigslist Reduced Violence Against Women * (Tech. Rep.). Retrieved from http://scunning.com/craigslist110.pdf

Cunningham, S., \& Kendall, T. D. (2016). Examining the Role of Client Reviews and Reputation within Online Prostitution. In The handbook of the economics of prostitution (pp. 9-31).

Dunn, M. J. (2018, sep). Younger Escorts Advertise Higher Charges Online than Older Escorts for Sexual Services CrossCulturally. Evolutionary Psychological Science, 4(3), 331-339. Retrieved from http://link.springer.com/ 10.1007/s40806-018-0142-z doi: 10.1007/s40806-018-0142-z

Elmes, J., Nhongo, K., Ward, H., Hallett, T., Nyamukapa, C., White, P. J., \& Gregson, S. (2014, dec). The price of sex: Condom use and the determinants of the price of sex among female sex workers in eastern Zimbabwe. Journal of Infectious Diseases, 210 (suppl 2), S569-S578. Retrieved from https://academic.oup.com/jid/ article-lookup/doi/10.1093/infdis/jiu493 doi: 10.1093/infdis/jiu493 
Fournet, N., Koedijk, F. D. H., van Leeuwen, A. P., van Rooijen, M. S., van der Sande, M. A. B., \& van Veen, M. G. (2016, feb). Young male sex workers are at high risk for sexually transmitted infections, a cross-sectional study from Dutch STI clinics, the Netherlands, 2006-2012. BMC infectious diseases, 16, 63. Retrieved from/http://www.ncbi.nlm.nih.gov/pubmed/26847196http://www.pubmedcentral .nih.gov/articlerender.fcgi?artid=PMC4743128 doi: 10.1186/s12879-016-1388-3

Government Equalities Office. (2018). TRANS PEOPLE IN THE UK. Retrieved from https://assets .publishing.service.gov.uk/government/uploads/system/uploads/attachment\{_\}data/file/ 721642/GEO-LGBT-factsheet.pdf

Griffith, J. D., Capiola, A., Balotti, B., Hart, C. L., \& Turner, R. (2016, jun). Online female escort advertisements: The cost of sex. Evolutionary Psychology, 14(2), 1-9. Retrieved from http://journals.sagepub.com/doi/ 10.1177/1474704916651270 doi: 10.1177/1474704916651270

Holt, T. J., Blevins, K. R., \& Fitzgerald, S. (2016, dec). Examining the Economics of Prostitution Using Online Data. In S. Cunningham \& M. Shah (Eds.), The oxford handbook of the economics of prostitution (Vol. 1). Oxford University Press. Retrieved from http://oxfordhandbooks.com/view/10.1093/oxfordhb/ 9780199915248.001.0001/oxf ordhb-9780199915248-e-18www.oxfordhandbooks.com doi: 10.1093/ oxfordhb/9780199915248.013.18

Jones, A. (2015, jul). Sex Work in a Digital Era. Sociology Compass, 9(7), 558-570. Retrieved from http:// doi.wiley.com/10.1111/soc4.12282 doi: 10.1111/soc4.12282

Kremer, M., \& Morcom, C. (1998, jul). The effect of changing sexual activity on HIV prevalence. Mathematical biosciences, 151(1), 99-122. Retrieved from http://www.ncbi.nlm.nih.gov/pubmed/9664761

Mai, N. (2009). Migrant Workers in the UK Sex Industry (RES-062-23-137) - Research Report. Esrc, 16-26. Retrieved from http://arxiv.org/abs/cond-mat/0104480 doi: 10.1136/thx.2010.150896.acknowledgements

Mattson, G. (2015, jun). The modern career of 'the oldest profession' and the social embeddedness of metaphors. American Journal of Cultural Sociology, 3(2), 191-223. Retrieved from http://link.springer.com/10 .1057/ajcs.2015.4 doi: 10.1057/ajcs.2015.4

Mowlabocus, S., \& Wood, R. (2015, jul). Introduction: audiences and consumers of porn. Porn Studies, 2(2-3), 118-122. Retrieved from http://www.tandfonline.com/doi/full/10.1080/23268743.2015.1056465 doi: $10.1080 / 23268743.2015 .1056465$

Office for National Statistics. (2019). Exploring the UK's digital divide - Office for National Statistics. Retrieved 2019-07-17, from https://www.ons.gov.uk/peoplepopulationandcommunity/ householdcharacteristics/homeinternetandsocialmediausage/articles/ exploringtheuksdigitaldivide/2019-03-04

ONS. (2014). National Accounts Articles-Impact of ESA95 Changes on Current Price GDP Estimates (Tech. Rep.). Office for National Statistics. Retrieved from https://webarchive.nationalarchives.gov.uk/ 20160108141658/http://www.ons.gov.uk/ons/dcp171766\{_\}365274.pdf

Platt, L., Grenfell, P., Bonell, C., Creighton, S., Wellings, K., Parry, J., \& Rhodes, T. (2011, aug). Risk of sexually transmitted infections and violence among indoor-working female sex workers in London: the effect of migration from Eastern Europe. Sexually Transmitted Infections, 87(5), 377-384. Retrieved from http://www.ncbi.nlm .nih.gov/pubmed/21572111http://sti.bmj.com/cgi/doi/10.1136/sti.2011.049544 doi: 10.1136/ sti.2011.049544

Robinson, B. A. (2015, apr). "Personal Preference" as the New Racism. Sociology of Race and Ethnicity, 1(2), 317330. Retrieved from http://journals.sagepub.com/doi/10.1177/2332649214546870 doi: 10.1177/ 2332649214546870

Rocha, L. E. C., Liljeros, F., \& Holme, P. (2010, mar). Information dynamics shape the sexual networks of Internet-mediated prostitution. Proceedings of the National Academy of Sciences of the United States of America, 107(13), 5706-11. Retrieved from http://www.ncbi.nlm.nih.gov/pubmed/20231480http://www . pubmedcentral.nih.gov/articlerender.fcgi?artid=PMC2851932 doi: 10.1073/pnas.0914080107

Scambler, G. (2007, dec). Sex Work Stigma: Opportunist Migrants in London. Sociology, 41(6), 10791096. Retrieved from http://journals.sagepub.com/doi/10.1177/0038038507082316 doi: 10.1177/ 0038038507082316

UK Home Affairs Committee. (2017). House of Commons Home Affairs Committee Prostitution Third Report of Session 2016-17 (Tech. Rep.). Retrieved from https://publications.parliament.uk/pa/cm201617/cmselect/ cmhaff/26/26.pdf

Van Hoorebeek, M. (2014). Exceptions to copyright infringement. In Law, libraries and technology (pp. 75-110). Retrieved from https://www.gov.uk/guidance/exceptions-to-copyright doi: 10.1016/b978-1-84334 $-071-3.50007-\mathrm{x}$ 


\section{Appendices}

\begin{tabular}{ll} 
Grouped Nationality & Nationalities \\
\hline \hline Britain & British, British (Manx) \\
\hline Middle East & Yemenite, Turkish, Iranian, Kuwaiti, ... \\
\hline Eastern Europe & $\begin{array}{l}\text { Romanian, Moldovan, Polish, Hungarian, Czech, Latvian, } \\
\text { Lithuanian, Bulgarian, Slovakian, Russian, Slovenian, Ukrainian, Croatian, ... }\end{array}$ \\
\hline \multirow{2}{*}{ Western Europe } & $\begin{array}{l}\text { Spanish, German, Maltese, Greek, Danish, Finnish, } \\
\text { Swedish, French, Italian, Portuguese, Irish, Dutch, } \\
\text { Icelander, Maltese, Austrian, Norwegian, ... }\end{array}$ \\
\hline Asia & $\begin{array}{l}\text { Chinese, Indian, Thai, Malaysian, Singaporean, } \\
\text { Chinese (Hong Kong), Sri Lankan, Bangladeshi, Japanese, ... }\end{array}$ \\
\hline Oceania & Filipino, Australian, New Zealander, ... \\
\hline North America & American, Canadian \\
\hline Central and South America & Mexican, Brazilian, Argentinian, Chilean, Colombian, Ecuadorian, ... \\
\hline
\end{tabular}
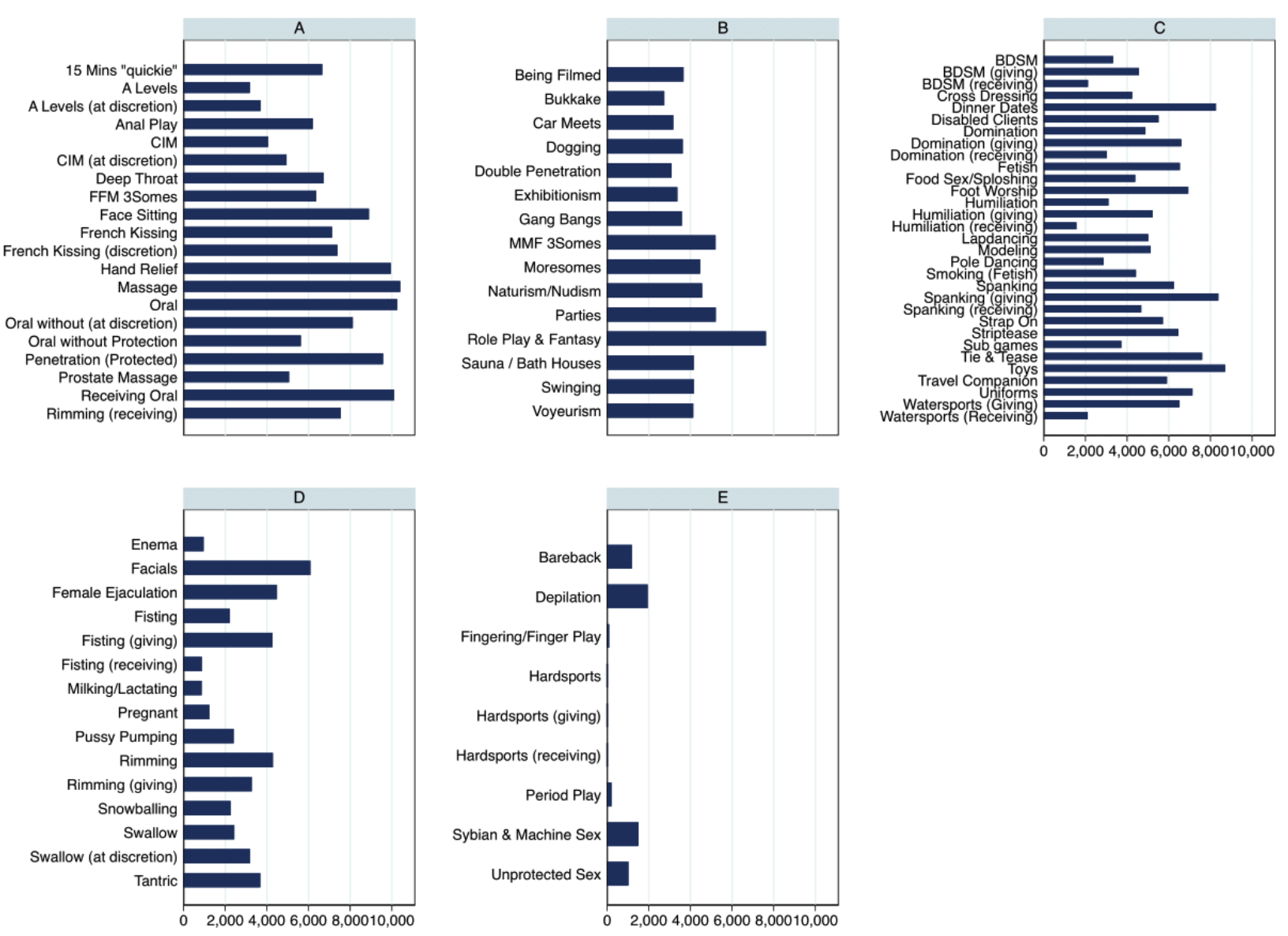

Figure 8: Count of workers providing services by category. 


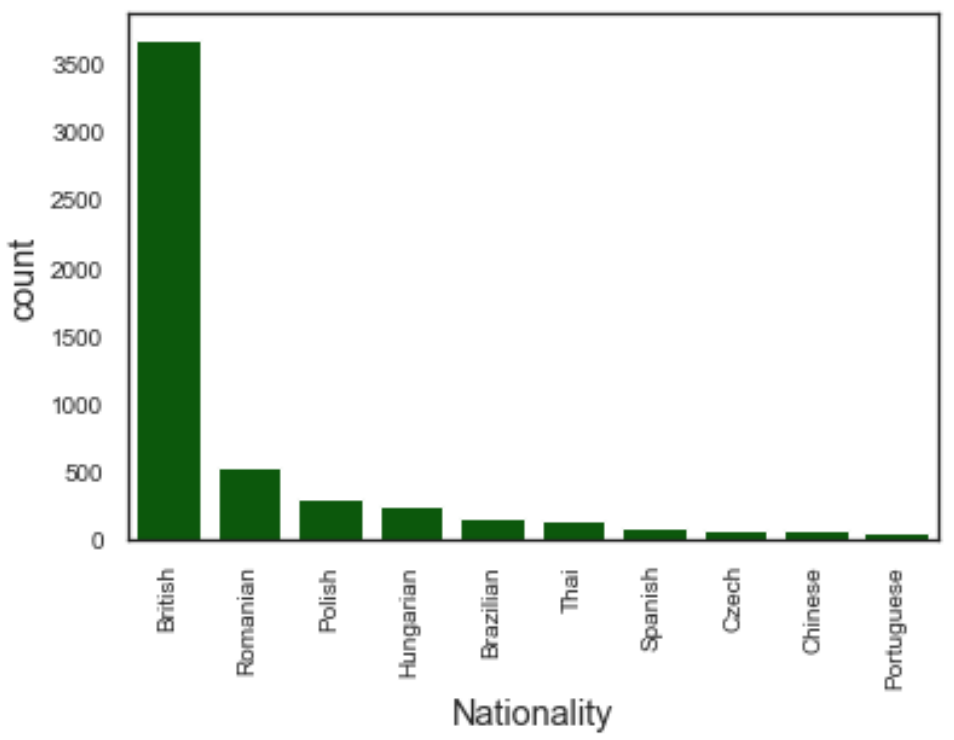

Figure 9: Top 10 nationalities of workers.

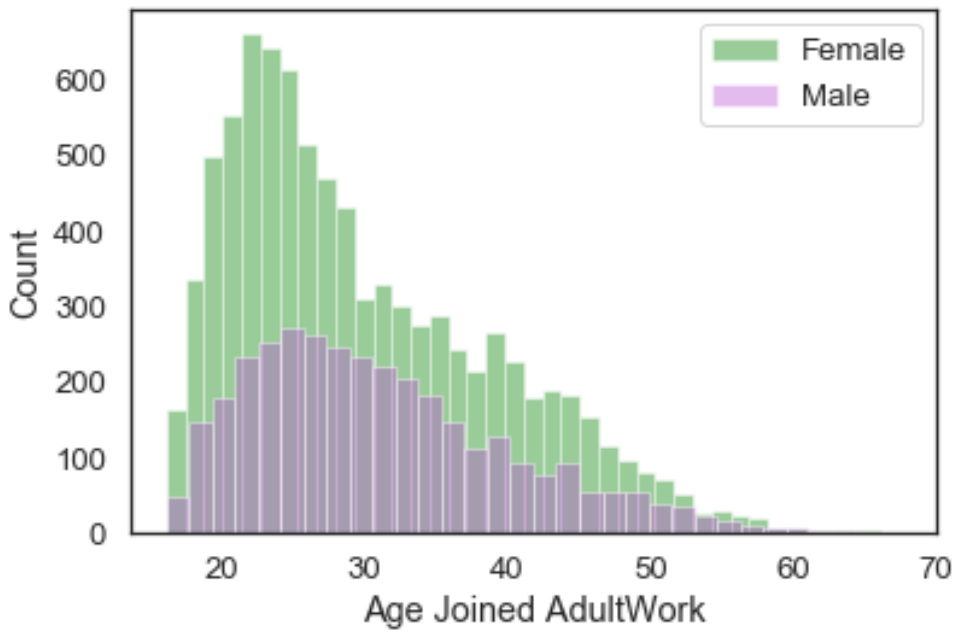

Figure 10: Age of joining the platform by gender. 

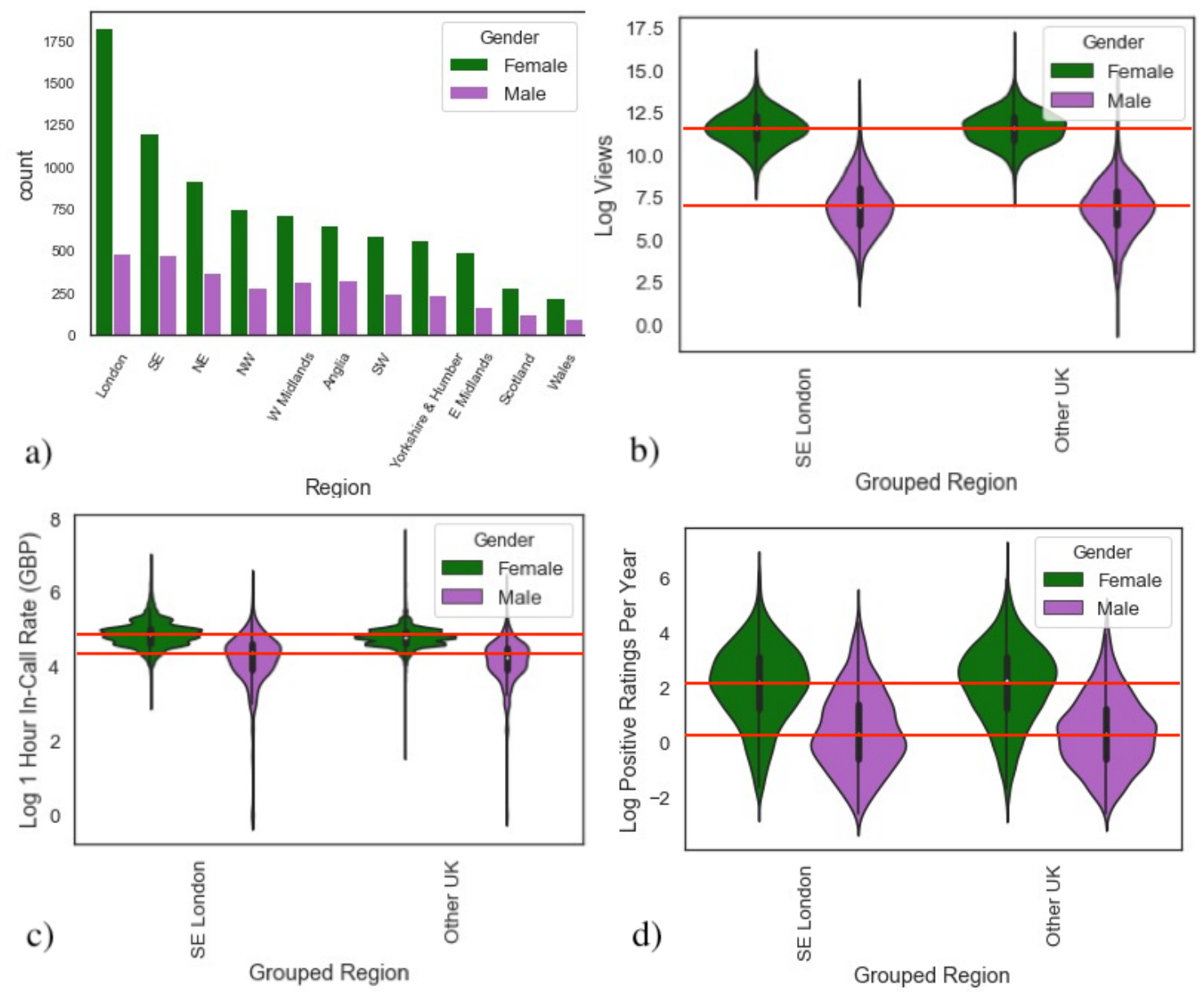

Figure 11: a) Distribution of region, b) views, c) rate, and d) ratings for different region groups 

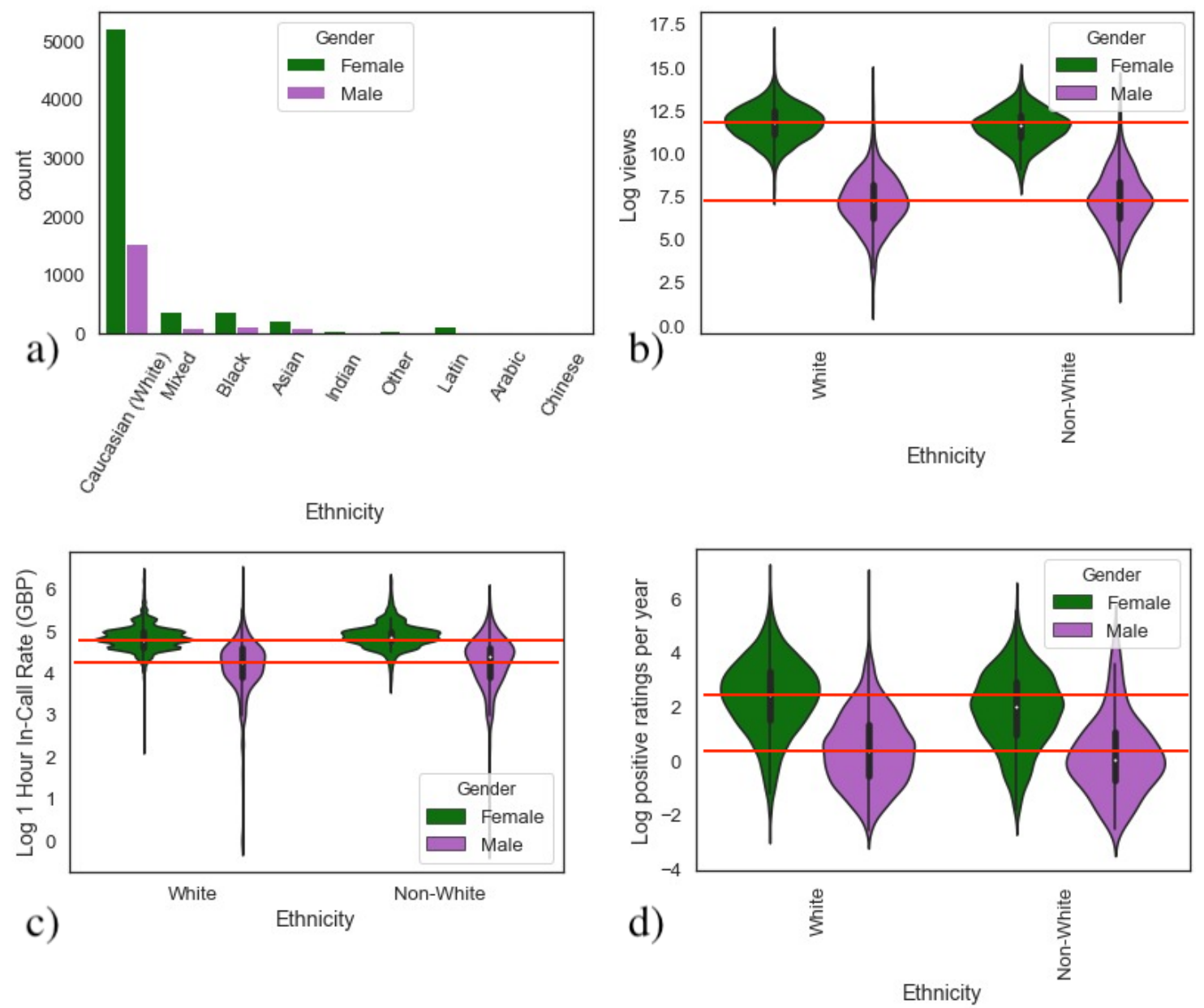

Figure 12: a) Distribution of Grouped ethnicity, b) views, c) rate, and d) ratings by ethnicity. 

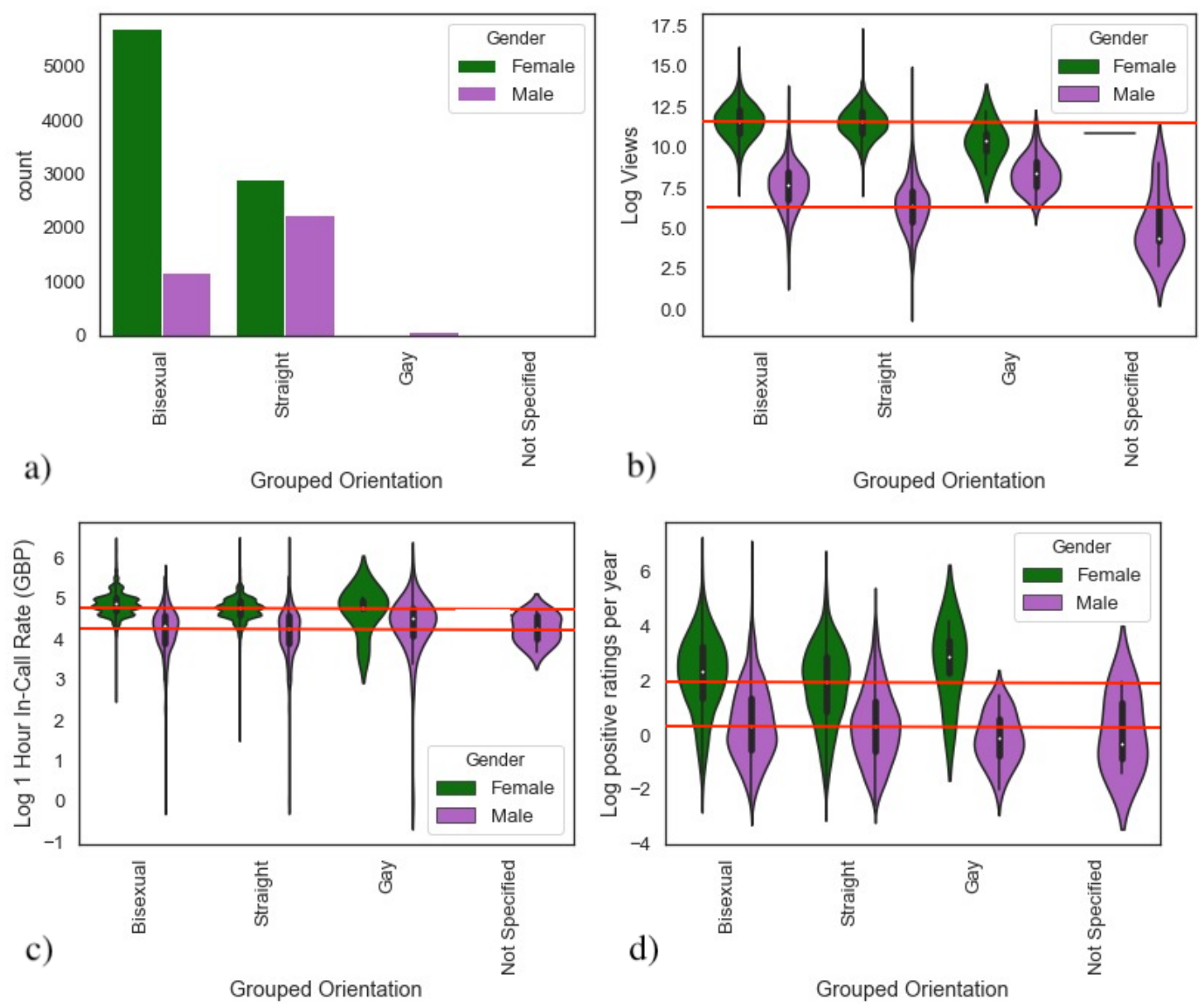

Figure 13: a) Distribution of orientation b) views, rate, and ratings by orientation. 